\title{
Los estados confederados de América: carácter nacional y política exterior hacia México, 1861
}

\author{
Gerardo Gurza Lavalle \\ INSTITUTO MORA
}

\begin{abstract}
Al inicio de la guerra de secesión en Estados Unidos, los estados confederados trataron de legitimar su lucha independentista mediante la consagración de ciertos principios, valores y creencias que debían constituir la base ideológica de la nueva nación. Esa ideología nacional ejerció una influencia considerable en la actuación de la efímera república sureña en la escena internacional y, particularmente, en sus relaciones con México.
\end{abstract}

$\mathrm{D}$ urante la guerra civil de Estados Unidos, los estados sureños trataron de conservar los principios ideológicos que les proporcionaban una identidad y una justificación para aspirar a la independencia.

El análisis del ámbito interno se ha convertido, desde hace ya algunas décadas, en una preocupación hasta cierto punto habitual de los estudiosos de las relaciones internacionales. Al margen de las distintas preferencias de enfoque, la certeza de que los problemas del entorno doméstico desempeñan siempre un papel importante en la actuación de los países en la escena mundial es ya un presupuesto de aceptación generalizada.

Sin embargo, entre los numerosos factores internos que cuentan con el potencial para influir tanto en el diseño de una determinada política exterior, como en el curso de las relaciones de una nación con otra, no todos han merecido la misma atención por parte de los historiadores. La comprensible tendencia a establecer jerarquías ha conducido a los especialistas de este campo a desdeñar aquellos elementos que no se prestan fácilmente al trazo de relaciones de causalidad directa y que, por lo mismo, no parecen de- 
sempeñar un papel central. Una de las víctimas principales de ese desdén ha sido la ideología, pues su presencia en los estudios de historia diplomática ha quedado por lo común subordinada con respecto a otros factores.

En el caso de la historiografía estadunidense, si bien las tesis del realismo no gozan ya de la vigencia que alguna vez tuvieron, se ha conservado cierta resistencia a considerar a la ideología como una de las principales fuerzas en la determinación de la política exterior. Esto se manifiesta cuando se toma en cuenta que aun las corrientes historiográficas más inclinadas al análisis del ámbito interno, como la nueva izquierda, otorgaron a la ideología un papel de segundo orden, reconociéndola únicamente como un complemento de los intereses económicos, al suponerse que éstos constituían el resorte fundamental de la diplomacia de Washington. ${ }^{1}$

A pesar de lo anterior, el ejemplo estadunidense es quizá uno de los más notables e interesantes en cuanto a la repercusión que ciertos elementos ideológicos pueden tener en el desempeño internacional de las naciones. Prácticamente desde el momento en que Estados Unidos alcanzó su independencia, dio inicio la construcción de una identidad nacional basada en el mito del excepcionalismo y en la convicción de que la flamante república estaba llamada a realizar una misión liberadora y civilizadora en el mundo. Esta fe en una superioridad institucional, moral y social (con toda una serie de valores culturales y elementos ideológicos implícitos),

\footnotetext{
${ }^{1}$ Ninkovich, "Ideology", 1982, pp. 187-189.
}

así como la necesidad de definir y reafirmar lo que para efectos prácticos puede denominarse como carácter nacional, han intervenido de manera constante en el comportamiento internacional de Estados Unidos. ${ }^{2}$

Esto no equivale a decir que debamos confiar al examen de la ideología la tarea de producir una versión completamente nueva de la historia diplomática de Estados Unidos. Las relaciones internacionales, como cualquier otro proceso histórico, escapan a la tiranía de un factor determinante único. Sin embargo, reconsiderar el papel de la ideología y poner un énfasis mayor en ella bien puede abrir nuevas perspectivas y contribuir a incrementar nuestra comprensión de ciertos problemas.

En las siguientes páginas elaboraremos un análisis del vínculo entre ideología, política exterior y diplomacia en un episodio específico: las relaciones del Sur con México al inicio de la guerra civil estadunidense.

Desde varios años antes de tomar el camino de la secesión en 1861, los estados meridionales de la Unión habían iniciado la difícil tarea de confeccionar una ideología nacional propia. Sobre todo a partir de 1850, una elite de escritores, intelectuales, periodistas y políticos, hicieron lo posible para llamar la atención del público sobre aquellos rasgos de la sociedad sureña que más la distinguían de su contraparte septentrional. Este esfuerzo por definir con la mayor precisión posible un conjunto de características propias estaba dirigido a cumplir dos funciones esenciales: por una parte, convencer a la pobla-

\footnotetext{
${ }^{2}$ Hunt, Ideology, 1987, pp. 3-17.
} 
ción sureña de su unicidad cultural y fundamentar así un sentimiento nacionalista en ciernes; y por la otra, proporcionar a la comunidad internacional un cúmulo de evidencia sociológica de su individualidad $y$, por ende, de su viabilidad como futura nación. ${ }^{3}$ De esta manera, al resaltarse una serie de principios basados en la experiencia histórica, social y cultural de la región, gradualmente fue cobrando forma un núcleo ideológico definido, cuyos componentes de mayor relieve pueden resumirse así:

a) La convicción de que la esclavitud de la raza negra era algo positivo, moralmente intachable y tan benéfico para el propietario como para el esclavo.

b) Una fe absoluta en la doctrina de los derechos estatales, la cual prescribía un máximo de autonomía para los gobiernos locales y una esfera de acción estrictamente acotada para la autoridad federal, reconociendo sólo las atribuciones que el texto constitucional otorgaba a ésta de manera clara y explícita.

c) La certeza de ser, y de continuar siendo, una sociedad agraria apegada a la vida rural y a sus características; opuesta a la urbanización, la industrialización y sus inquietantes consecuencias sociales tal como éstas empezaban a manifestarse en el Norte. ${ }^{4}$

Sobra decir que existían otros elementọs y que esta simplificación de ninguna manera pretende dar cuenta cabal de algo tan complejo como la

\footnotetext{
${ }^{3}$ En estos aspectos, el ejemplo sureño es similar al de muchos otros nacionalismos decimonónicos. Véase Smith, Theories, 1983, p. 215.

${ }^{4}$ Para esta esquematización nos basamos en Thomas, Confederacy, 1972, pp. 1-22.
}

ideología sureña. Sin embargo, puede sostenerse que el ideario de los estados meridionales fue edificado, en medida considerable, sobre estos tres pilares.

Debe hacerse mención, asimismo, de un elemento que, si bien no podía equipararse en importancia con los tres anteriores, tenía una indudable presencia en el pensamiento de la región: el expansionismo. Los estados sureños habían tenido razones políticas y económicas de mucho peso para buscar la anexión de territorios en México y en el Caribe. La motivación política más evidente obedecía al temor de convertirse en una minoría en el gobierno federal, especialmente a raíz de la admisión de California como estado libre en 1850 , hecho que marcó la desaparición del equilibrio Norte-Sur en el Senado. ${ }^{5}$ En el aspecto económico, el deseo de contar con una mayor reserva de tierras propicias para el cultivo del algodón también daba lugar a una intensa ambición por adquirir nuevos territorios. ${ }^{6}$ Pero más allá de los indiscutibles fundamen-

${ }^{5}$ Hasta 1850 , tanto el Norte como el Sur tuvieron el mismo número de senadores. En cambio, en la cámara de representantes el equilibrio se había roto desde muchos años antes debido al acelerado incremento demográfico en los estados libres. Por ello, el ingreso de California a la Unión fue percibido por el Sur como una amenaza a sus intereses y dio lugar a tentativas de recuperar el equilibrio de poder regional mediante la anexión de nuevos territorios.

${ }^{6}$ Las motivaciones económicas del expansionismo han generado un interesante debate historiográfico, en cuyo análisis no es posible detenerse en esta breve exposición. Baste aquí con decir que es indiscutible que círculos influyentes de políticos, plantadores y periodistas percibían la anexión de territorios como una necesidad para la viabilidad a largo plazo del 
tos prácticos que alimentaban el fervor expansionista, el Sur había desarrollado su propia versión del Destino Manifiesto, con un programa de redención de los pueblos atrasados de México y el Caribe que contemplaba la introducción del trabajo esclavo y el establecimiento del dominio de la raza blanca. El expansionismo, como un proyecto grandioso, preñado de posibilidades y promesas de todo tipo, sedujo la imaginación popular y se convirtió en un anhelo compartido por sectores de toda la escala social sureña. ${ }^{?}$

Así pues, para el momento en que la proximidad de la contienda electoral de 1860 recrudeció las tensiones regionales, esa serie de certezas, convicciones y anhelos habían madurado en la conciencia sureña hasta conformar un núcleo ideológico ortodoxo, cerrado e intolerante. Las iglesias de las principales denominaciones religiosas del Sur -bautista, metodista y presbiterianahabían roto ya con sus congregaciones septentrionales debido a las críticas a la esclavitud; las escuelas y universida. des empezaban a retirar los libros de texto de autores norteños e instaban a los intelectuales coterráneos a producir sustitutos cuanto antes; la literatura declarada prohibida era quemada en hogueras y se cerraban imprentas sospechosas. $^{8}$ William Howard Russell, el

sistema esclavista y de la producción algodonera a gran escala. Véase Ramsdell, "Natural", 1929, passim; Genovese, Political, 1989, passim, y Ransom, Conflict, 1989, pp. 54 y ss.

${ }_{7}^{7}$ Urban, "Ideology", 1956, pp. 53-55; May, Southern, 1989, passim.

${ }^{8}$ McCardell, Idea, 1979 , pp. 204-207, 226; Thomas, Confederacy, 1972, p. 34. famoso periodista británico que visitó la Confederación al comienzo de la guerra civil, registró en su diario de viaje las observaciones de un ciudadano sureño acerca del carácter de su pueblo:

Nosotros somos un pueblo de agricultores $[\ldots]$ No tenemos ciudades ni deseamos tenerlas $[. .$.$] No tenemos marina$ comercial ni marina de guerra y tampoco las queremos. Estamos mejor sin ellas [...] No deseamos tener clase mercantil, ni clase trabajadora o clase manufacturera $[\ldots]{ }^{9}$

De esta manera, el Sur iniciaría su aventura como nación independiente con una ideología definida y con una percepción clara de las características que lo distinguirían como nación: una república esclavista y agraria, con un sistema político basado en la doctrina de los derechos estatales y, quizá también, expansionista.

La ruptura con la Unión, y la guerra que posteriormente sostuvieron los estados sureños para afirmar su independencia, adquirieron legitimidad como parte de un esfuerzo esencialmente conservador; la nueva nación sólo podía justificar su razón de ser en un afán de preservar los principios y valores compartidos que se encontrarían amenazados de permanecer en la Unión. En consecuencia, la autonomía política debía plantear una continuidad casi perfecta con el cuerpo ideológico desarrollado durante el periodo previo, y la congruencia exigía que las medidas del nuevo gobierno fueran el medio para cristalizar esa ideología en accio-

${ }^{9}$ Citado por Luraghi, "Civil", 1972, p. 241. 
nes concretas. ${ }^{10}$ Sin embargo, la dirigencia confederada no tardó en percibir los inconvenientes que su bagaje ideológico planteaba para la construcción de un gobierno viable y también para una conducción adecuada de varios aspectos del ejercicio público.

Los primeros indicios de que la Confederación estaba dispuesta a tomar cierta distancia del ideario sureño de la preguerra surgieron durante los debates de la asamblea que redactaría la nueva constitución. En términos generales, puede decirse que en la elaboración de la Carta Magna dominó la opinión de aquellos sureños que admitían la necesidad de limitar los rasgos más radicales del credo ortodoxo. ${ }^{11}$ La nueva ley fundamental no sólo prohibía el comercio internacional de esclavos, sino que además dejaba la puerta abierta para que estados no esclavistas pudieran ingresar a la Confederación. ${ }^{12}$ Pero a pesar de este aparente triunfo inicial de la moderación, en realidad el debate entre la visión de mundo heredada del periodo anterior, por una parte, y una postura más flexible y dis-

\footnotetext{
${ }^{10}$ Faust, Creation, 1988, p. 21. La profunda convicción de que el Sur había tomado el camino de la secesión "no para cambiar sino para preservar" apareció con frecuencia en las explicaciones que los agentes confederados proporcionaron a los gobiernos extranjeros. Véase, para citar sólo un ejemplo, John Slidell a Edouard Thouvenel, París, 21 de julio de 1862 en Records of the Confederate States of America (en adelante RCSA), vol. 3 , rollo 3 .

${ }^{11}$ Vandiver, "Confederacy", 1962, p. 281; Thomas, Confederate, 1979 , pp. 56-66.

${ }^{12}$ Constitution of the Confederate States of America, artículo I, sección 9 y artículo IV, sección 3. La Constitución puede consultarse en Davis, Rise, 1990, vol. 1, apéndice K, pp. 559 y ss.
}

puesta al cambio, por la otra, estaba muy lejos de quedar resuelto; esta pugna entre una ideología que parecía definir el carácter de la nueva nación, con sus demandas de continuidad, y una actitud pragmática, atenta a las circunstancias así como a los requerimientos inéditos de la guerra y de la edificación de un Estado sólido, constituyó sin duda uno de los ejes centrales de la breve historia de la Confederación. Sobra decir que las contradicciones de ese antagonismo afectaron profundamente varios aspectos del desempeño de la república sureña, y entre ellos, por supuesto, el de la política exterior.

¿Qué clase de política se perseguiría con respecto a las regiones antes percibidas desde una perspectiva meramente expansionista? No era necesario realizar cálculos demasiado complicados para intuir que la ambición anexionista tradicional debía ceder terreno ante la urgencia de establecer relaciones cordiales y asegurar la neutralidad de los vecinos, México principalmente y Cuba (España) en menor medida. Y aunque todo parece indicar que esta certeza no escapó a la visión del Departamento de Estado confederado, no es menos cierto que, desde el principio, los encargados de definir el curso diplomático que se seguiría con respecto a México permitieron que también los viejos anhelos entraran en juego.

La misión de viajar a México para iniciar relaciones cordiales, y garantizar que este país permaneciera neutral durante la contienda civil en Estados Unidos, recayó en la persona de John T. Pickett. Este hombre originario de Kentucky había ocupado el consulado estadunidense en Veracruz a lo largo 
de varios años (1853-1858 y 1860 1861), de manera que tenía cierta experiencia en asuntos mexicanos y conocía personalmente a algunos de los liberales más prominentes. ${ }^{13}$ Pickett debió su nombramiento a la intercesión de John Forsyth -ministro plenipotenciario en México de 1856 a 1858quien escribió directamente a Jefferson Davis para recomendarlo, ${ }^{14}$ anexando a su carta un documento en el que el propio Pickett exponía sus ideas acerca de los objetivos que la diplomacia confederada debía procurar con respecto a su vecino del Sur. En dicho documento, Pickett señalaba la necesidad de impedir por cualquier medio que el gobierno de Washington llevara a cabo sus planes de expansión económica y colonización en el norte de México. Debía hacerse, además, todo lo posible para evitar que los gobiernos de Lincoln y Juárez concluyeran un acuerdo de alianza o cualquier convenio que resultase perjudicial para los intereses del Sur. En caso de que el régimen liberal decidiera tomar partido por el Norte, la Confederación podría prestar su apoyo a la facción conservadora y ayudarla a retomar el poder. Por otra parte, enfatizando que el Sur no debía descuidar su "herencia" en esa parte del continente, Pickett agregaba:

Me parece innecesario hacer algo más que una alusión, en esta apresurada nota, a las inmensas ventajas que los

${ }^{13}$ La larga gestión de Pickett en Veracruz no ha recibido atención suficiente. Para un tratamiento muy general véase Berbusse, "Two", 1975, pp. 501.512.

${ }^{14}$ John Forsyth a Jefferson Davis, Washington, 20 de marzo de 1861 en RCSA, vol. 4 , rollo 4 .
Estados Confederados recibirían en lo futuro de los ilimitados recursos agrícolas y minerales de México, así como de la posesión del invaluable tránsito interoceánico por el istmo de Tehuantepec. Hacia el Sur está nuestro destino, y no debemos mirar con indiferencia los muy patentes designios de nuestros enemigos en aquella región. ${ }^{15}$

Esta breve exposición por parte de Pickett debió bastar para que Jefferson Davis y su secretario de Estado, Robert Toombs, quienes con toda probabilidad leyeron este escrito, llegaran sin dificultad a la conclusión de que su autor no sería el hombre más adecuado para procurar un buen entendimiento entre la Confederación y México. Sobre todo si se tomaba en cuenta que la posibilidad de contar con cierta cooperación, o aun con la absoluta neutralidad de parte del segundo, estaría supeditada a la capacidad de convencer al gobierno de Juárez de que un Sur independiente no planteaba amenaza alguna a la integridad territorial de su país.

Con todo, Pickett fue finalmente designado agente confidencial para representar a su gobierno en México; y para hacer todavía más difícil una posible evaluación de los verdaderos propósitos de la Confederación, se le extendió un pliego de instrucciones en el que dominaba un tono por demás discreto y mesurado. En ellas se indicaba al agente que no solicitara el reconocimiento diplomático del Sur ni tampo. co una recepción oficial, pues bastaba con que el gobierno de Juárez se mos-

\footnotetext{
15 Pickett a Forsyth, Washington, 13 de marzo de 1861 en RCSA, vol. 4, rollo 4 .
} 


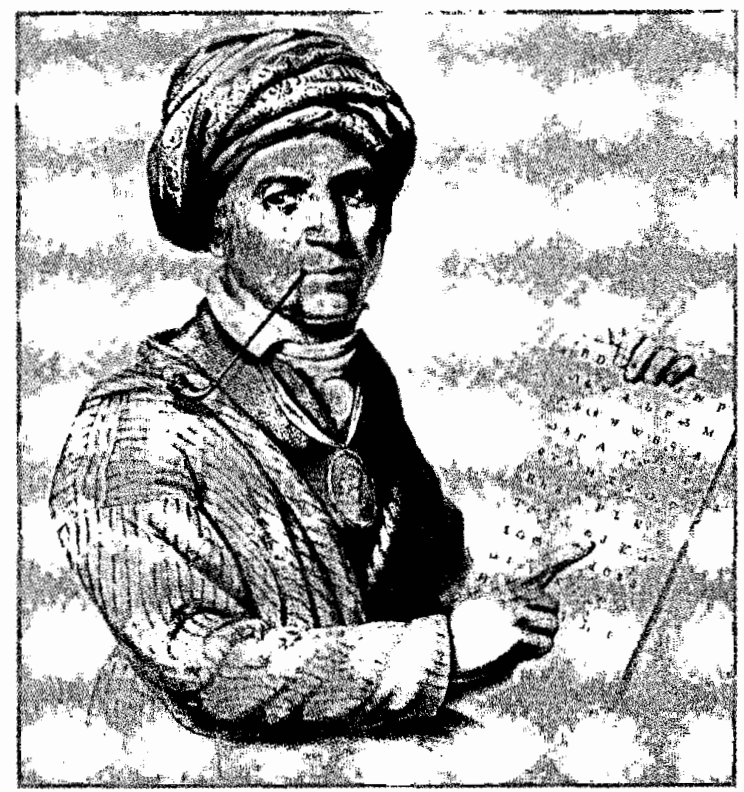

trase dispuesto a sostener un intercambio amistoso y confidencial. Además de esto, y de otros puntos de escasa relevancia, destacaba nada más una demanda de tono enérgico: aunque la Confederación no podía oponerse a que México, en su capacidad soberana, celebrara convenios con Estados Unidos, sí exigía la observación de la más estricta neutralidad y anticipaba su intención de protestar "pronta y decididamente" si alguno de ellos implicara concesiones o ventajas especiales ("comerciales, políticas o territoriales") que no fueran extendidas también al Sur. ${ }^{16}$

\footnotetext{
16 Robert T'oombs a Pickett, "General instructions", Montgomery, 17 de mayo de 1861 y "Me-
}

Como se ve, estas sencillas instrucciones reflejaban únicamente las preocupaciones inmediatas de la Confederación y, por tanto, implicaban una separación de las tendencias expansionistas típicas de los años cincuenta. Una consideración, incluso superficial, de las circunstancias imperantes en 1861, apunta también a la conclusión de que la república sureña no estaba a la sazón en condiciones de aventurarse en proyectos de engrandecimiento territorial, toda vez que la guerra con el Norte demandaba todo su potencial, y, por otro lado, la expectativa de lograr un pronto reconocimiento di-

morandum of instructions for mister Pickett" (anexo al anterior) en RCSA, vol. 4, rollo 4. 
plomático por parte de las potencias europeas marcaba la necesidad de seguir una línea prudente de conducta exterior. Para reforzar lo anterior, basta traer a cuenta el hecho de que en agosto de 1861 Santiago Vidaurri, en ese entonces gobernador de Nuevo León y Coahuila, invitó discretamente al gobierno sureño a iniciar negociaciones para la incorporación de los estados bajo su mando a la Confederación, oferta que, pese a su generosidad, fue rechazada sin titubeos por Jefferson Davis. ${ }^{17}$ En suma, la interpretación de que el régimen rebelde estaba dispuesto a aprovechar la primera oportunidad que se le presentara para apropiarse de territorio mexicano carece de solidez.

Ahora bien, lo que queda por esclarecer es el motivo de la elección de Pickett para viajar a México a sabiendas de que se trataba de un devoto de la versión sureña del Destino Manifiesto y, más todavía, el por qué de la aceptación, al menos implícita, que se dio a sus opiniones sobre la política exterior más conveniente para el frente diplomático mexicano. Esto último cobra mayor relieve cuando se toma en cuenta que las ideas expresadas en la carta citada con anterioridad tuvieron un peso decisivo en su gestión.

Es necesario detenerse brevemente en los rasgos más significativos del desempeño de Pickett en .México para después intentar una explicación.

${ }^{17}$ José A. Quintero a Robert M. T. Hunter, Richmond, 19 de agosto de 1861, en RCSA, vol. 58, rollo 32; William M. Browne a Quintero, Richmond, 3 de septiembre de 1861 en RCSA, vol. 12 , rollo 10 .
Al llegar a su destino, el agente confederado se encontró con un escenario poco favorable a los intereses de la nación sureña, pues, prácticamente desde el inicio, pudo darse cuenta de que el gobierno de Juárez abrigaba mayores simpatías hacia el bando norteño. Aun antes de que abandonara Veracruz para desplazarse hacia la capital, alcanzaron sus oídos ciertos rumores en el sentido de que aquél había concedido a Estados Unidos un permiso para que sus tropas pudieran cruzar territorio mexicano con el objeto de atacar a la Confederación por la retaguardia. En un principio pensó que esa información no era digna de crédito, pero como medida preventiva hizo circular la audaz insinuación de que si llegaba a otorgarse dicho permiso, México incurriría en una ruptura de neutralidad tan grave que justificaría una declaración de guerra por parte del Sur. ${ }^{18}$ Algunos días después, ya en la ciudad de México, Pickett comunicaba con tranquilidad a sus superiores que todo parecía indicar que el gobierno de Juárez no sería capaz de cometer un error de esa magnitud, sobre todo debido a que había complementado sus advertencias declarando en repetidas ocasiones que en el momento en que se concediera un permiso como ese, "30 000 agentes diplomáticos cruzarían la frontera" para hacer manifiesta su inconformidad. ${ }^{19}$

Éste fue el comienzo de una cadena casi interminable de ejemplos que de-

\footnotetext{
${ }^{18}$ Pickett a Toombs, Jalapa, 27 de junio de 1861, despacho núm. 2, en RCSA, vol. 5 , rollo 5 .

19 Pickett a Toombs, México, 11 de julio de 1861, despacho núm. 3, en RCSA, vol. 5 , rollo 5 .
} 
notaban la absoluta carencia de tacto diplomático por parte del agente sureño. Sin embargo, en este caso, las amenazas de invasión al menos obedecían a un propósito específico y consistente con el contenido de sus instrucciones, o sea, impedir que México confiriese al gobierno de Washington cualquier privilegio que pudiera utilizarse en perjuicio de la Confederación. Pero la retórica expansionista de Pickett no tardó en aflorar en su correspondencia en una forma que hacía pensar que la anexión de territorios constituía también uno de los objetivos de su misión. En las conversaciones que sostenía con miembros de la comunidad extranjera y de los círculos políticos locales, se le preguntaba con frecuencia si el Sur no estaría acaso, ansioso por adquirir más territorio mexicano. Pickett se apresuraba a contestar que esas ambiciones eran cosa del pasado, pues desde que la Confederación había declarado su independencia el resorte más evidente del expansionismo sureño (la necesidad de mantener el equilibrio de poder con el Norte) había dejado de existir. No obstante, en los despachos dirigidos a sus superiores el ex cónsul en Veracruz expresaba su verdadero sentir:

No debe suponerse, a partir de este lenguaje diplomático, que no esté yo completamente convencido del hecho de que el Destino Manifiesto podría desmentir las afirmaciones anteriores. iNadie lleva más fija en la mente que el que esto escribe la gran verdad de que la estrella del imperio tomará su camino hacia el Sur! ${ }^{20}$

${ }^{20}$ Pickett a Toombs, México, 1 de agosto de 1861, despacho núm. 5 , en RCSA, vol. 5 , rollo 5 .
Posteriormente, el problema del permiso para el tránsito de tropas de la Unión por la ruta de Guaymas a Arizona proporcionó también varias oportunidades para que Pickett manifestara con toda libertad su vocación expansionista. Dicha concesión había sido aprobada por el Congreso el 20 de junio de $1861,{ }^{21}$ y las autoridades mexicanas, ante las protestas del agente sureño, justificaron su decisión en la ignorancia de que la Confederación reclamaba el territorio de Arizona como parte de sus dominios. Así, desde la perspectiva del gobierno de Juárez, la licencia no constituía violación alguna de la neutralidad, puesto que sólo permitiría a las fuerzas estadunidenses transitar de una parte a otra de su propio territorio. ${ }^{22}$ En un principio, $\mathrm{Pi}$ ckett se mostró dispuesto a admitir esta excusa, conformándose con señalar que Arizona era un territorio en disputa y que, por lo tanto, México no podía aceptar la autoridad de Washington sobre el mismo sin adoptar implícitamente una postura parcial. ${ }^{23} \mathrm{Sin}$ embargo, al observar que el régimen libe-

\footnotetext{
21 Véase William H. Seward a Matias Romero, Washington, 7 de mayo de 1861; Romero al Ministro de Relaciones Exteriores, Washington, 8 de mayo de 1861; Romero a Seward, Washington, 26 de agosto de 1861, todas en Romero, Correspondencia, 1870, vol. 1, pp. 721-722, 508.

22 "Memoranda", John S. Cripps-Manuel María de Zamacona, México 17 de agosto de 1861, en RCSA, vol. 5, rollo 5; Zamacona a Romero, México, 8 de septiembre de 1861 en Tamayo, Benito Juárez, 1965, vol. 4, p. 763.

${ }^{23}$ Pickett a Toombs, México, 25 de agosto de 1861, despacho núm. 7; Pickett a Toombs, México, 28 de agosto de 1861, despacho núm. 8 , en RCSA, vol. 5 , rollo 5 .
} 
ral no sólo no rescindía el permiso, sino que además sostenía misteriosas negociaciones con el ministro estadu. nidense, ${ }^{24}$ empezó a sugerir medidas drásticas. En octubre de 1861 el agente sureño recomendó a sus superiores que dispusieran el envío de un contingente militar a Monterrey con la finalidad de retener esa ciudad como garantía de la neutralidad mexicana hasta que pudiera lograrse un acuerdo de paz con el Norte. Según el agente sureño, si esa ocupación era bien ejecutada nada impediría que toda la región del noreste mexicano pasara permanentemente a manos confederadas. En esta forma, el permiso de tránsito y la cada vez más ostensible parcialidad del gobierno de Juárez con respecto de la Unión dejaban de constituir un motivo de preocupación, pues, percibidos de una manera adecuada, en realidad representaban una "oportunidad de oro" para que los Estados Confederados adelantaran "una parte de ese inevitable destino que los impulsa hacia el Sur". ${ }^{25}$

Éste y otros pasajes similares de la correspondencia de Pickett han sido interpretados por varios autores como una prueba contundente de que la Confederación, guardando estricta coherencia con sus antecedentes, procu-

\footnotetext{
${ }^{24}$ Por esos dias se estaba negociando el Tratado Corwin-Zamacona, mediante el cual el gobierno de Juárez esperaba obtener un préstamo de 9000000 de dólares, ofreciendo como garantia de pago todos los terrenos públicos y la propiedad eclesiástica nacionalizada de los estados de Baja California, Sonora, Chihuahua y Sinaloa. Schoonover, Dollars, 1978, pp. 55 y ss.

${ }^{25}$ Pickett a Toombs, México, 29 de octubre de 1861, despacho núm. 12, en RCSA, vol. 5, rollo 5 .
}

raba abiertamente objetivos anexionistas con respecto a su vecino. Según estas versiones, Pickett fue la elección lógica de un régimen comprometido con el esclavismo y con el expansionismo, y no existía contradicción alguna entre los excesos retóricos del agente sureño y la política exterior de su gobierno. $^{26}$

No obstante, resulta muy difícil sostener esta interpretación si se toman en cuenta los elementos que ya se han mencionado, a saber: la absoluta inoportunidad de una política de este tipo en la coyuntura de la guerra civil (la probable apertura de un segundo frente de guerra, el desvio de recursos de por sí escasos y el rechazo internacional automático) y, evidencia quizá más elocuente, la repulsa de Jefferson Davis a la sorprendente oferta de Santiago Vidaurri. Por si esto no bastara, puede agregarse el hecho de que el departamento de Estado sureño no recibió más que dos despachos de Pickett, ambos carentes de importancia, y que sus mensajes restantes fueron interceptados, por lo que su contenido permaneció desconocido hasta que Pickett, ya de regreso en el Sur, entregó personalmente un juego completo de copias. En consecuencia, el gobierno confederado no estuvo enterado de

${ }^{26}$ Véanse, por ejemplo, Hendrick, Statesmen, 1939, p. 119; McCornack, "Estados", 1955, pp. 336-339, 342; Owsley, King, 1931, pp. 92 y ss. Fuentes Mares incluye un breve capítulo sobre Pickett en Juárez, 1962, pp. 94-107, pero no aborda esta cuestión. Schoonover, Dollars, 1978, pp. 13-48 presenta quizá el mejor análisis de la misión de Pickett, aunque no toma una postura clara en torno a cuáles eran los objetivos del gobierno confederado. 
manera oportuna del proceder de su agente y, es obvio, no tuvo ocasión de aprobar su conducta. ${ }^{27}$ Por el contrario, existen indicios significativos de que Pickett cayó en desgracia más tarde debido a los desatinos cometidos durante su misión. Ciertos documentos posteriores revelan que a su regreso a la Confederación se le cerraron todas las puertas y que los altos funcionarios del gobierno empezaron a manifestarle una franca antipatía. De hecho, en una carta dirigida a Jefferson Davis dos años después, Pickett llegó a disculparse por la extravagancia que lo había caracterizado durante su desempeño. ${ }^{28}$

Hace falta, entonces, responder a la pregunta planteada páginas atrás: ipor qué se envió a México a un hombre cuyas opiniones se sabían de antemano divergentes de la pretendida moderación que la dirigencia sureña deseaba en su política exterior?

Una posible respuesta puede buscarse en las profundas' contradicciones ideológicas que la vorágine de la guerra civil deparó a la Confederación. Al momento de iniciar su lucha armada por la independencia, la nación sureña tuvo que enfrentar una difícil paradoja: la fundación de un gobierno propio y la elevación de la otrora ideología regional al rango de ideología nacional llevaron consigo una inevitable exaltación

\footnotetext{
27 William H. Browne a Pickett, Richmond, 30 de noviembre de 1861 y Pickett a Browne, Veracruz, 31 de diciembre de 1861, ambos en RCSA, vol. 4, rollo 4 .

${ }^{28}$ Pickett a Jefferson Davis, Richmond, 11 de enero de 1864 . Véase también la nota que cierra su cuaderno de despachos, fechada en enero de 1868 en Toronto. Ambos en RCSA, vol. 5, rollo 5 .
}

de los elementos fundamentales del ideario sureño; de manera simultánea, los encargados de edificar el nuevo Estado no tardaron en cobrar conciencia de que los pilares del carácter nacional resultaban particularmente inadecuados para arrostrar las exigencias de una guerra de magnitudes desconocidas, o incluso para sentar las bases de un orden institucional y político viable.

A lo largo de los cuatro años que duró la contienda, la Confederación atravesó por un proceso de profundas transformaciones; un transcurso lleno de problemas nuevos e inesperados que implicó un alejamiento cada vez más notorio del pensamiento ortodoxo heredado de la etapa previa. La república ideal, cimentada en un gobierno federal débil y en una vigorosa autonomía local, así como en la indiscutible superioridad social y económica de la producción agrícola y del régimen laboral esclavista, pronto quedó subordinada a las necesidades prácticas. El gobierno sureño se convirtió gradualmente en una agencia de centralización, arrogándose numerosas atribuciones propias del ámbito estatal y ampliando su esfera de acción hasta abarcar áreas antes vedadas. El Sur agrícola se transformó, por otra parte, en productor de un sinnúmero de manufacturas necesarias para el esfuerzo bélico, provocando con ello el crecimiento de una clase trabajadora doméstica y su concentración en núcleos urbanos. ${ }^{29}$ En lo que se refiería a la esclavitud, la oferta de abolición reali-

\footnotetext{
${ }^{29}$ Vandiver, "Confederacy", 1962, pp. 284 285; Luraghi, "Civil", 1972, p. 246; Thomas, Confederacy, 1972, pp. 60-69.
} 
zada a las potencias europeas a cambio del reconocimiento diplomático, en marzo de 1865 , si bien fue una medida última y desesperada, constituye quizá la muestra más palpable de los cambios operados durante esos cuatro años. Tal como señala un autor, esta oferta fue el signo de que la independencia dejaba de ser un medio para conservar la forma de vida sureña y se convertía en un fin valioso por sí mismo. ${ }^{30}$

Este tránsito al pragmatismo, sin embargo, no fue automático ni resultó fácil. Por el contrario, se llevó a cabo a regañadientes y contra la opinión de aquellos que pensaron que se estaban perdiendo de vista los motivos de la lucha. Se trató de un complejo debate interno que generó innumerables contradicciones. ${ }^{31}$

Estos contrasentidos debieron tener amplias repercusiones en la política exterior de la Confederación. En el caso de México, la renuncia a los antiguos anhelos expansionistas no podía darse de manera instantánea. Incluso los abanderados de la moderación, representantes de la actitud realista y más preocupada por la procuración de metas asequibles, no pudieron desvincular tajantemente sus políticas de los viejos intereses. En este sentido, es válido considerar la gestión de Pickett como un epítome de la pugna entre el credo recalcitrante y la postura más ajustada a las necesidades del momento. Su nombramiento puede interpretarse como un síntoma de la indefinición que privaba en el gobierno sureño al atravesar la paradójica coyuntura de exaltación

${ }^{30}$ Thomas, Confederacy, 1972, p. 131.

${ }^{31}$ Faust, Creation, 1988, p. 85. de la vieja ideología y, a la vez, de reconocimiento de su inutilidad para las circunstancias presentes; las demandas de continuidad de valores, creencias y principios como cimiento de la nueva nación, y la conciencia de la necesidad de introducir modificaciones.

La aceptación tácita de las opiniones de Pickett refleja en buena medida la renuencia a borrar de manera definitiva una ambición que englobaba significados profundos para el pensamiento sureño, pero sobretodo constituyó una aprobación de principios abstractos que no implicaban necesariamente un programa de acción. La retórica expansionista de Pickett no proponía una estrategia con pasos claramente enunciados, pues sólo hacía referencia a los anhelos tradicionales en un plano ideal. De esta manera, el gobierno confederado bien podía tolerar o incluso simpatizar con un discurso visionario, que no involucraba plan concreto alguno, sin perder por ello de vista cuál sería la línea de conducta exterior más adecuada para el contexto de la guerra civil. Sólo así se explica que se hayan dado por buenas las opiniones de Pickett al mismo tiempo que le eran entregadas unas instrucciones concebidas para guiar un desempeño moderado y prudente. Los problemas surgieron cuando el agente confederado se sintió autorizado para llevar sus impresiones a la práctica, tomando iniciativas que concordaban con su percepción pero que se separaron cada vez más del contenido de sus instrucciones. Al actuar de este modo Pickett mostraba su propia confusión, ya que interpretó su nombramiento como una confirmación de que su parecer 
coincidía con los criterios del departamento de Estado sureño.

De esta manera, la primera tentativa diplomática confederada con respecto a México ${ }^{32}$ se encontró con el fracaso que su indefinición le preparaba de antemano, pues, como ya se mencionó, la mayoría de los despachos de Pickett fueron interceptados en el correo y llegaron a manos de Juárez y sus ministros, ${ }^{33}$ quienes al leer su contenido no hicieron sino confirmar sus simpatías por el Norte y su repudio hacia la Confederación.

Así, aunque la dirigencia sureña hizo lo posible por suspender la vigencia de los antiguos ideales, al menos durante el tiempo que durase la guerra,

\footnotetext{
${ }^{32}$ En términos generales, puede hablarse de tres tentativas o ensayos diplomáticos de la Confederación en México. La primera está representada en la misión de Pickett. La segunda se desarrolló en la zona fronteriza (Texas, Coahuila, Nuevo León y Tamaulipas) y tuvo como principales protagonistas a las autoridades locales de ambos lados de la frontera. La tercera constituyó un intento por utilizar a México como instrumento para lograr un acercamiento con Francia durante la guerra de intervención. Este esfuerzo se llevó a cabo en París, pues el objeto era convencer a Napoleón III de que la viabilidad del imperio mexicano dependía por completo de la independencia del Sur. Véase Gurza, "Vecindad", 1998.

${ }^{33}$ El mismo Pickett pudo enterarse de que éste había sido el procedimiento que sistemáticamente se había seguido con sus despachos cuando, al hacer una escala en Tampico durante su viaje de regreso a la Confederación, el encargado local de correos le confió que por órdenes superiores había detenido toda su correspondencia, enviándola de vuelta a la ciudad de México. Los pormenores de este incidente se describen en Pickett a Jefferson Davis, Richmond, 11 de enero de 1864, en RCSA, vol. 5, rollo 5 .
}

la vigorosa influencia de éstos se filtró continuamente al desempeño de un gobierno que trataba de sacrificarlos a la vez que seguía reconociendo su valor para mantener la coherencia de la visión de mundo que le había dado origen.

\section{BIBLIOGRAFÍA}

-Berbusse, Edward J., "Two kentuckians evaluate the mexican scene from Veracruz, 1853-1861", The Americas, vol. 31, núm. 4, 1975.

-Davis, Jefferson, The rise and fall of the Confederate Government, Da Capo Press, Nueva York, 1990, 2 vols.

-Faust, Drew Gilpin, The creation of confederate nationalism. Ideology and identity in the civil war South, Louisiana State University Press, Baton Rouge, 1988.

-Fuentes Mares, José, Juárez y la Intervención, Jus, México, 1962.

-Genovese, Eugene D., The political economy of slavery. Studies in the econo$m y$ and society of the slave South, Wesleyan University Press, Middletown Connecticut, 1989.

-Gurza Lavalle, Gerardo, "Una vecindad efímera; Los Estados Confederados de América y su política exterior hacia México, 1861-1865", tesis de maestría, Instituto Mora, 1998.

-Hendrick, Burton J., Statesmen of the lost cause. Jefferson Davis and bis cabinet, Little, Brown and Company, Boston, 1939.

-Hunt, Michael, Ideology and U. S. foreign policy, Yale University Press, New Haven, 1987.

-Luraghi, Raimondo, "The civil war and the modernization of american society: social structure and industrial revolution in the old south before and during the war", Civil War History, vol. 18, núm. 3, 1972. 
-McCardell, John, The idea of a southern nation. Soutbern nationalists and southern Nationalism, 1830-1860, W. W. Norton \& Co., Nueva York, 1979.

-McCornack, Richard Blaine, "Los Estados Confederados y México", Historia Mexicana, vol. 4, núm. 3, 1955.

-May, Robert E., The soutbern dream of a caribbean empire. 1854-1861, University of Georgia Press, Athens, Georgia, 1989.

-Ninkovich, Frank, "Ideology, the open door and foreign policy", Diplomatic History, vol. 6, núm. 2, 1982.

-Owsley, Frank L., King cotton diplomacy. Foreign relations of the Confederate States of America, The University of Chicago Press, Chicago, 1931.

-Ramsdell, Charles W., "The natural limits of slavery extension", Mississippi $\mathrm{Va}$ lley Historical Review, vol. 16, 1929.

-Ransom, Roger L., Conflict and compromise. The political economy of slavery, emancipation and the civil war, Cambridge University Press, Nueva York, 1989.

-Romero, Matías (comp.), Correspondencia de la Legación mexicana en Washington durante la intervención extranjera. 1860-1868. Colección de documentos para formar la bistoria de la intervenciôn, Imprenta del Gobierno, México, 1870,10 vols.

-Schoonover, Thomas D., Dollars over dominion. The triumph of liberalism in mexican-United States relations, 18611867, Louisiana State University Press, Baton Rouge, 1978.

-Smith, Anthony D., Theories of nationalism, Holmes \& Meier Publishers, Nueva York, 1983.

-Tamayo, Jorge L. (comp.), Benito Juárez. Documentos, Discursos y Correspondencia, Secretaría del Patrimonio Nacional, México, 1965, 15 vols.

- Thomas, Emory, The Confederacy as a revolutionary experience, University of South Carolina Press, Columbia, Corolina del Sur, 1972.

1861-1865, The confederale nation Nueva York, 1979.

-Urban, C. Stanley, "The ideology of southern imperialism: New Orleans and the Caribbean, 1845-1860", Louisiana Historical Quarterly, vol. 39, núm. 1, 1956.

-Vandiver, Frank E., "The Confederacy and the american tradition", Journal of Soutbern History, vol. 37, núm. 3, 1962. 